\title{
Propensity Score Analysis of the Impacts of Junior Secondary Students' Participation in Engineering Practices on their Attitudes toward Engineering
}

\author{
Xiaohong Zhan ${ }^{1}$, Daner Sun ${ }^{2 *}$, Chunchun Qiang ${ }^{3}$, Rui Song ${ }^{3}$, Zhi Hong Wan ${ }^{2}$ \\ ${ }^{1}$ College of Teacher Education, Faculty of Education, East China Normal University, Shanghai, CHINA \\ ${ }^{2}$ The Education University of Hong Kong, HONG KONG \\ ${ }^{3}$ East China Normal University, CHINA
}

Received 5 December 2018 • Revised 8 April 2019 • Accepted 10 April 2019

\begin{abstract}
The demand for engineering talent is increasing with economic and societal developments. Along with this, nations worldwide are attaching increasing importance to engineering education under international science, technology, engineering and mathematics initiatives. In China, engineering education at university levels is dominant. Corresponding systemic engineering education at the $\mathrm{K}-12$ level has yet to be established. With the aim of determining the status of $\mathrm{K}-12$ engineering education, this study investigates the impacts of students' participation in engineering practice on their attitudes toward engineering. Survey responses from a sample of 2,193 students from junior secondary schools in Shanghai, China, are used. Sample selection bias is mitigated using propensity score methods based on weight hierarchy. The findings indicate the status of student participation in engineering practice and reveal the significant effect of the level of student participation in engineering practice on students' attitudes toward engineering at junior secondary schools in China.
\end{abstract}

Keywords: engineering practice, attitudes toward engineering, propensity score method

\section{INTRODUCTION}

With the initiatives of science, technology, engineering and mathematics (STEM) education, both the value for engineering education worldwide and the demand for engineering talent (following economic and social advancements) have increased (Brophy et al., 2008; Chabalengula \& Mumba, 2017; Maeng et al., 2017; Puente et al., 2011). The most serious challenge encountered in many countries is developing new approaches to engineering education at the K-12 level that encourage students to consider and pursue engineering careers (Brophy et al., 2008; Kutnick et al., 2018; Silver \& Rushton, 2008; Wiebe, Unfried, \& Faber, 2018). Various efforts have been made to integrate and improve engineering education in science, such as the publication of education documents (e.g., $A$ Framework for K-12 Science Education and Next Generation Science Standards [NGSS] in the US, the China Primary Science Curriculum Standard and The National Curriculum in England) that emphasise the integration of engineering into K-12 education (China Ministry of Education, 2017; NGSS, 2013; NRC, 2012; UK Department of Education, 2013). Engineering and technology should be integrated into the structure of science education at the same level as scientific inquiry (NGSS, 2013). As such, new global science education reforms have fostered a connection between engineering and science education to better prepare students and society to meet the current and future challenges of a modern and technological world (Bybee, 2011; Chabalengula \& Mumba, 2017; Guzey \& Ring-Whalen, 2018; Strimel \& Grubbs, 2016).

Following science education reforms in other nations and the prosperity of STEM education, China has designed its own initiatives and plans for promoting engineering education at the K-12 level. For example,

(C) 2019 by the authors; licensee Modestum Ltd., UK. This article is an open access article distributed under the terms and conditions of the Creative Commons Attribution License (http://creativecommons.org/licenses/by/4.0/).

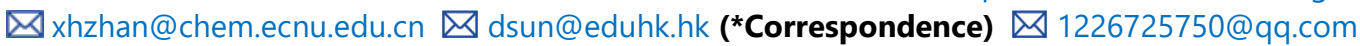




\section{Contribution of this paper to the literature}

- A series of literature review has been conducted to discuss the current challenges and status of engineering education in and out of China. The literature review was the initial efforts on exposing the current status of engineering education in science curriculum.

- Few studies on students' participation in engineering practices have been conducted by the use of propensity score analysis. The research findings exposed the relationship of students' participation in engineering practices and their attitudes toward engineering in micro levels, with addressing three dimensions of students' participation.

- The findings will inform the science curriculum design and development, the engineering design in science curriculum, as well as STEM teacher education.

'technology and engineering' has been introduced as one of the four key learning areas (i.e., materials, life, earth and universe) in the Primary Science Curriculum Standard (MOE, 2017). This has led to the suggestion that integrating engineering with science education can improve students' understanding of scientific knowledge and mastery of engineering skills and enhance their STEM-related knowledge and problem solving skills (Brophy, Klein, Portsmore, \& Rogers, 2008; Gunstone, 1994; Tang \& Wang, 2014). This marks the official position of engineering in science curricula, with aims to improve students' science learning and develop their interests in and career orientation towards engineering in China (Gao, 2017). Consistent with the promotion of STEM education, research projects, research centres, school-based curricula and professional teacher development efforts emphasising engineering have also been developed (Gao, 2013; Liu, 2017; MOE, 2012; National Institute of Education Sciences, 2017; Wu, 2015; Xie, Zhang, \& Lai, 2014).

Many studies have indicated that the attitude students develop towards engineering at the K-12 level is the key factor in their pursuit of engineering-related and STEM majors or careers (Apedoe et al., 2008; LaForce, Noble, \& Blackwell, 2017; Perrin, 2004). Many publications have stressed the primary goal for engineering education at the K-12 level as the enhancement of students' understanding of engineering and interest in engineering and engineering-related occupations (American Society for Engineering Education [ASEE], 1987; Capobianco et al., 2013; Committee on Standards for K-12 Engineering Education, 2010; NAE, 2005; NGSS, 2013; NRC, 2009). An awareness of the attitudes toward engineering developed in K-12 education would provide the foundation and conditions for higher-level engineering education (Tseng et al., 2013; Unfried et al., 2015). However, studies have revealed that K-12 students' interest in engineering is fading in many countries and that too few students pursue engineering majors in college (Budassi \& Rafailovich, 2018; Cerinsek et al., 2013; Franz-Odendaal et al., 2016). This leads to the development of engineering talents barely meets societal needs (Felder \& Brent, 2005; Wang, Ye, \& Degol, 2017). Similarly, engineering education starts late and mostly focuses on tertiary education in China. First, little coverage of engineering in K-12 education exists. Second, most engineering practice is interwoven in science curricula or some co-curricular activities at the primary level. Third, gaps are present in the engineering education between primary and secondary levels. Thus, students receive little exposure to systemic engineering education and learning experiences. To a large extent, this negatively affects their pursuit of engineering-related majors and careers and the development of engineers in society (Hayden et al., 2011; Kutnick et al., 2017; UNESCO, 2010). A review of the literature also shows that the majority of studies has focused on exploring students' attitudes toward engineering and STEM subjects (de Vries, 2016; Unlu, 2016). However, few studies have explored the factors underlying students' attitudes towards engineering by investigating their participation in engineering practice at the secondary level in Shanghai, China.

To address these issues, this study investigates the relationship between students' participation in engineering practice and their attitudes toward engineering. The propensity score method is used, as it can effectively mitigate bias and improve relevant variables. The findings reveal how Shanghai has implemented engineering practice in K-12 education and the impacts of this implementation on students' attitudes toward engineering.

\section{LITERATURE REVIEW}

\section{K-12 Engineering Education}

The demand for engineering talents has increased with the rapid developments in science and technology and with the continuous progression of human civilisation. The advancement of engineering education is expected to facilitate social and economic improvement and engineering innovation. Furthermore, the number of countries and territories paying more attention to education in the engineering or related fields has increased in recent years, resulting in a variety of engineering education systems with distinct features. This is especially true at the K-12 education level. 
Since the publishing of Science, Technology and Society: Science Education for the 1980s by the National Science Teachers Association (NSTA, 1982) and Science for All - Project 2061 by the American Association for the Advancement of Science (AAAS, 1985), the concept of K-12 engineering education, first proposed by the ASEE, has gradually become recognised worldwide. Related documents, including Engineering in K-12 Education: Understanding the Status and Improving the Prospects, were also published in the following years (Katehi et al., 2009). This further developed engineering education independently of math and science. The contents and methods of teaching and the mode of engineering education development at the primary and secondary school levels have been designed and implemented in alignment with those at the higher education level. Altogether, several million K-12 students have received formal engineering education and tens of thousands of teachers have attended professional development sessions to learn how to teach engineering-related coursework (Katehi et al., 2009). In the UK, the Netherlands, Singapore and Japan, engineering education has been integrated into the K-12 education system through the establishment of science and design and science and technology curricula (Abdulwahed, 2017; OECD, 2013). In Germany and Australia, a multilevel and diverse engineering talent development system has been formed as a result of systematic initiatives and plans for engineering education at the K-12 level (NAE, 2010). This has laid the foundation for engineering talent development and reservation at the higher education level.

\section{K-12 Engineering Education in China}

In China, the latest Primary Science Curriculum Standards (2017) include 'technology and engineering' and suggest that 'every child is a born engineer'. The integration of science and engineering education is expected to improve students' understanding of science and help them master engineering practice skills. Moreover, implementing science and engineering-integrated practice activities may enhance students' hands-on capabilities, nurture their creativity and improve their problem-solving skills (MOE, 2017). This is the first time that the role of engineering practice is being highlighted in science education in China.

Although the most extensive in scale, engineering education in China mainly focuses on higher education (Dong \& Liu, 2017; Xu, 2008). Because of the overall absence of engineering education at the K-12 level, students possess little relevant knowledge and encounter many problems in understanding and pursuing this discipline. This has a direct negative impact on the development of engineering education in higher education and the cultivation of engineering talents (Kutnick et al., 2017). Nevertheless, confronted with inadequate experience and the pressure of 'lessening the academic burden' on primary and secondary school students, establishing an independent engineering subject in the K-12 education system remains difficult. According to the White Paper of STEM Education in China (National Institute of Education Sciences, 2017), the country's K-12 STEM education is fragmented, with no complete, systematic plans for schools. Some engineering activities have been integrated into the science curricula, extra-curricular activities and STEM activities in primary schools (Zhang, 2018). However, no uniform secondary school curriculum corresponds to and continues the STEM education elements (i.e., engineering) practised in primary schools based on the nature of the curriculum modes. Interestingly, almost half of schools purchase their STEM-related curricula from education research organisations or companies (GETChina Insights, 2017).

\section{Engineering Practice in Science Education}

Researchers have provided different definitions of engineering practice. Before analysing the concept of engineering practice, the definition of engineering must be discussed. According to the Accreditation Board for Engineering and Technology (ABET), engineering is the profession in which knowledge of the mathematical and natural sciences gained by study, experience and practice is applied with judgment to develop ways to economically utilise the materials and forces of nature for the benefit of mankind. According to Rogers (1983), engineering refers to the practice of organising the design and construction of any artefacts that transform the physical world to meet some recognised need. In A Framework for K-12 Science Education, engineering is defined as 'any engagement in a systematic practice of design to achieve solutions to particular human problems' (NRC, 2012, p. 11). Engineers use their understanding of mathematics and science to find solutions to ill-structured problems (Dankenbring, Capobianco, \& Eichinger, 2016). Following this line of thought, engineering practice is the process of producing artefacts that meet social needs based on scientific and mathematical knowledge and technical approaches (Moore et al., 2015; Sheppard et al., 2006). Engineering practice is at the core of engineering education, as it enables students to experience engineering work, to better understand the relations between engineering and science and to further their understanding by solving real problems (NRC, 2012). Eight forms of science and engineering practice have been identified: 1) asking questions (science) and defining problems (engineering); 2) developing and using models; 3) planning and conducting investigations; 4) analysing and interpreting data; 5) using mathematics and computational thinking; 6) constructing explanations (science) and designing solutions (engineering); 7) engaging in arguments based on evidence; and 8) obtaining, evaluating and communicating 
information. This framework is a good representative for integrating science and engineering in cohesive ways (NGSS, 2013).

With the spread of STEM education and the deepening of research into science and engineering practices, the modes of engineering integration into science have been modified. For example, Nam, Lee and Paik (2016) proposed a theoretical framework for meaningful engineering integration into K-12 science classrooms. Their framework consists of three components: 1) defining the problem and conducting background research about heat and heat transfer; 2) planning and implementing an initial prototype design; and 3) testing and evaluating the design. Following this curriculum, the students in their study developed positive attitudes toward science and demonstrated improved engineering practice. Peterman et al. (2017) developed a rubric to evaluate engineeringinfused science lessons. The evaluation helped expose the strengths and weakness of the lessons for teachers in STEM education. In recent years in China, the amount of research on classroom instruction models of engineeringintegrated science has increased. Using case studies of instruction models, strategies and approaches, researchers have identified patterns of engineering-integrated science instruction (Feng, 2016; Tang, 2014; Zhan, 2011). However, most studies of science engineering-integrated instruction models have mainly been carried out at the theoretical level. Few empirical studies on the effectiveness of different models of science engineering integration have been conducted.

\section{Relevant Studies on Students' Attitudes toward Engineering}

The science and engineering talent pool has decreased in recent years (Falco \& Summers, 2019; Smith \& White, 2019). Researchers and policymakers have elucidated that students' interest in STEM may be the most important factor in their choice of STEM-related careers (Becker, 2010; Hazari et al., 2018). Meanwhile, many studies have indicated that students' attitudes toward engineering cultivated at the K-12 level play a key role in their pursuit of engineering-related majors and careers. Tseng et al. (2013) indicated that students with positive attitudes toward engineering learning believe that engineering benefits society. Students' attitudes toward engineering directly affect their career choices. Smail (1993) highlighted the significance of interest in and passion for learning in K-12 education. He argued that without a strong passion for engineering learning at the K-12 level, students cannot develop positive attitudes toward engineering at the intermediate and higher education levels.

Specifically, Seymour and Hewitt (1997) identified students' deteriorating attitudes toward science as the major cause of their deteriorating attitudes toward engineering. Another cause results from the distraction of other subjects. Besterfield-Sacre et al. (2001) suggested that students' attitudes toward engineering are related to their gender and background of ethics. Capobianco, Yu and French (2015) explored the impact of engineering designbased science learning on students' understanding of engineering as a profession. They found that such understanding plays a decisive role in forming an orientation towards engineering-related careers. Karatas et al. (2010) found that sixth graders in the US have little or patchy understanding of engineering. However, other studies have revealed that students regard engineering as an interesting and useful subject. Hilpert (2008) discovered that students who enjoy the learning of science and math believe that these two subjects are the basis for studying and understanding engineering. These students demonstrated positive attitudes toward studying engineering because they believe that engineering benefits society and want to pursue engineering-related careers. Further research has also shown the positive role that extra-curricular science projects play in significantly improving students' attitudes toward engineering (Gerber, Olson, \& Komarek, 2012).

Few studies have explored the impacts of student participation in engineering practice on their attitudes toward engineering. This study aims to uncover the causal effects of junior secondary school students' participation in engineering practice on their attitudes toward engineering using survey data from junior secondary school students in Shanghai, China.

\section{PURPOSES AND RESEARCH QUESTIONS}

Quantitative research was conducted to explore the impacts of students' participation in engineering practice on their attitudes towards engineering. The findings were used to answer the following research questions:

1) What is the status of students' participation in engineering practice in junior secondary schools?

2) What are the impacts of students' participation in engineering practice on their attitudes toward engineering? 


\section{METHODOLOGY}

\section{Participants}

In this study, 2,785 junior secondary 1 (Grade 7, age 12-13) and secondary 2 (Grade 8, age 13-14) students were randomly selected from six inner-city schools (i.e., in Xuhui District and Pudong New District) and four suburban schools (i.e., in Minhang District and Qingpu District) in Shanghai, China. Of these schools, 30\% were private and $70 \%$ were public. The students participated in the study on a voluntary basis. They filled out a survey during their science classes at the end of the 2017/2018 school year. A total of 2,193 survey responses were obtained from 1, 215 junior secondary 1 students and 978 junior secondary 2 students. Of them, 1,383 were from public schools and 810 were from private schools. Furthermore, 1,933 were from inner-city schools and 260 were from suburban schools.

\section{Research Design and Instruments}

\section{Propensity score analysis}

Proposed by Rosenbaum and Rubin in the 1980s, propensity score analysis is a popular statistical method of processing data for causal inference. However, it often accomplishes the opposite of its intended goal, increasing imbalance, inefficiency, model dependence and bias (King \& Nielsen, 2018; Rosenbaum \& Rubin, 1983). It has been used in various fields (i.e., medicine, economy and education). This method can help contain confounding bias by combining several confounding variables into one propensity score and by balancing the propensity score of the compared groups to proportionate the distribution of confounding variables (Brookhart et al., 2013). Therefore, the propensity score method was adopted to effectively control confounding bias in sampling. As such, the interference from confounding variables was mostly avoided, allowing for better interpretation of the causal relationship between the students' engineering practice participation and their attitudes toward engineering.

The propensity score method has three stages: 1) propensity scoring, 2) matching and 3) analysis after matching. The explanatory, explained and confounding variables must be set according to the given research needs. The logistic (or probit) regression model must also be established. The matching method is decided at the last stage, after the prediction of the propensity score and causal relationships are examined. In this study, the explanatory variable, students' participation in engineering practice, was a sequential variable. Therefore, a sequential logistic regression model was used to predict the propensity score and stratified weighting, a more scientific method, was used in the sample matching stage.

\section{Variables and measures}

Three variable types were investigated: 1) the explanatory variable (i.e., the students' participation in engineering practice); 2) the explained variable (i.e., the students' attitudes toward engineering); and 3) the confounding variables (i.e., the students' demographics, social economic status, family information, school features and performance).

Explanatory variable. The frequency of participation in engineering activity (i.e., the number of engineering activities in which they participated in one semester) and the completeness of engineering activity (i.e., the engineering process of activities) were adopted as the indicators of students' participation level in engineering practice (Fredericks et al., 2004). Based on prior studies, the following engineering processes were adopted in designing the survey questions and identifying the engineering processes the students experienced: 1) questions were posed based on prior studies' real situations; 2) solutions were designed; 3) models and prototypes were constructed; and 4) products were optimised and improved (Ken, Kirby, \& Bober, 2016; NGSS, 2013; NRC, 2012; Sheppard et al., 2006).

Currently, in China, engineering practice at the K-12 level is mainly integrated with science learning. As such, three expert junior secondary science teachers and two university science educators were consulted to identify criteria for the participation levels of engineering practice along with consideration of the engineering process. Specifically, Level 1 indicates no participation; Level 2 indicates inactive participation (i.e., fewer than 5 times per semester); Level 3 indicates moderate participation (i.e., 5 times or more per semester, but an incomplete engineering process); and Level 4 indicates active participation (i.e., 5 times or more per semester, but a complete engineering process (Bazid \& Umar, 2014). Table 1 provides details of the participation levels of engineering practice. 
Table 1. Participation levels of engineering practice

\begin{tabular}{|c|c|c|}
\hline Level & Frequency (Times/Semester) & Engineering Process \\
\hline Level 1 & 0 & - \\
\hline Level 2 (Inactive ) & $<5$ & - \\
\hline Level 3 (Moderate ) & $>=5$ & (N) Incomplete \\
\hline Level 4 (Active) & $>=5$ & (Y) Complete \\
\hline
\end{tabular}

Note: " $\mathrm{Y}$ " indicates complete engineering practice and " $\mathrm{N}$ " indicates incomplete engineering practice

Table 2. Survey questions for participation level of engineering practices

\begin{tabular}{ll}
\hline Questions & Corresponding values of Answers \\
\hline \begin{tabular}{ll}
17.1 Design or create products to satisfy certain needs (e.g. design and create a water & Never -1 \\
filter) & $1-4$ times -2 \\
\hline 17.2 Would like to use limited time, money and resources to design and create products & $5-10$ times -3 \\
\hline
\end{tabular}$-10$ times -4
\end{tabular}

18.1 Propose engineering design problems based on some problems or acquired

knowledge (e.g. propose the problem that how to turn polluted water into drinkable water) Never 1

18.2 Propose solutions to the problem (e.g. using principles of water purification to design 1 - 4 times -2 water filter)

18.3 Develop products to solve problems (e.g. develop a simple water filter) 5 - 10 times -3

18.4 Point out why some products fail to function properly and think about how to improve them (e.g. how to improve the water filter so it can work better)

Two survey questions were designed to measure the student participation levels in engineering practice. Q17 questioned the frequency of participating in engineering practice and Q18 questioned whether students go through the complete engineering process. Q17 comprised two items. If a value of 1 was provided for both items, the student's participation frequency was coded as ' 0 times per semester'. If values of 1 and 2,2 and 1 or 2 and 2 were provided, the student's participation frequency was coded as ' $<5$ times per semester'. In other situations, the student's participation frequency was coded as ' $\geq 5$ times per semester'. Q18 comprised four items. If a value of 1 was provided for all four items, then the student's engineering process was coded as 'incomplete'. In other situations, it was coded as 'complete'. Table 2 provides details of survey questions.

Explained variable. In social psychology research, an attitude is defined as 'a psychological tendency that is expressed by evaluating a particular entity with some degree of favor and disfavor' (Bohner \& Dickel, 2011; Eagly \& Chaiken, 1993). The cognitive, affective and behavioural responses of attitude have been well acknowledged (Bohner \& Dickel, 2011; Eagly \& Chaiken, 1993; Rajeck, 1990; Reid, 2006). Adopting these conceptions, the students' attitudes toward engineering was investigated from the following dimensions: 1) cognition of engineering (i.e., thoughts, beliefs and ideas about engineering; 2) emotion towards engineering (i.e., feelings or emotions that engineering evokes); and 3) behavioural tendency towards engineering (i.e., tendency or disposition to act in certain ways towards engineering).

The engineering attitude survey included 21 questions. The design of the questionnaire was based on the three dimensions mentioned above. Six sub-dimensions were identified under cognition: 1) understanding of the nature of engineering $(\mathrm{Q} 1,2) ; 2)$ understanding of engineering education $(\mathrm{Q} 7,11) ; 3)$ understanding of the social value of engineering and engineering education $(\mathrm{Q} 4,8) ; 4)$ understanding of the educative value of engineering and engineering education $(Q 3,10) ; 5)$ understanding of engineering practice processes $(Q 5,15)$; and 6) understanding of engineering-related careers $(\mathrm{Q} 12,19)$. Four sub-dimensions were identified under emotion: 1) like engineering practice $(\mathrm{Q} 6) ; 2)$ like engineering products $(\mathrm{Q} 9,16) ; 3)$ like engineering education (or engineering activities) (Q14, 18); and 4) feel satisfied and a sense of achievement after engineering practice (Q13, 17). The dimension of behavioural tendency was defined as one's orientation towards engineering-related careers (Q20, 21). The survey questions were designed based on previous research on attitudes toward engineering and revised from Gibbons et al. (2004), Guzey et al. (2014) and Unfried et al. (2015).

To evaluate validation, three experienced science teachers (with more than 3 years of teaching experiences) from junior secondary schools, two science educators from university and two researchers reviewed and discussed each item. To measure the students' attitudes toward engineering, a 5-point Likert scale was used. The scale ranged from 'strongly disagree' (with a value of 1) to 'strongly agree' (with a value of 5). The Cronbach's alpha was calculated to determine the internal consistency of all of the items (21 questions) with an acceptable reliability a-coefficient of 0.702 (George \& Mallery, 2003). The students' total scores on the survey indicated their attitudes toward engineering and their scores on each major/sub-dimension indicated their status on each specific dimension. 


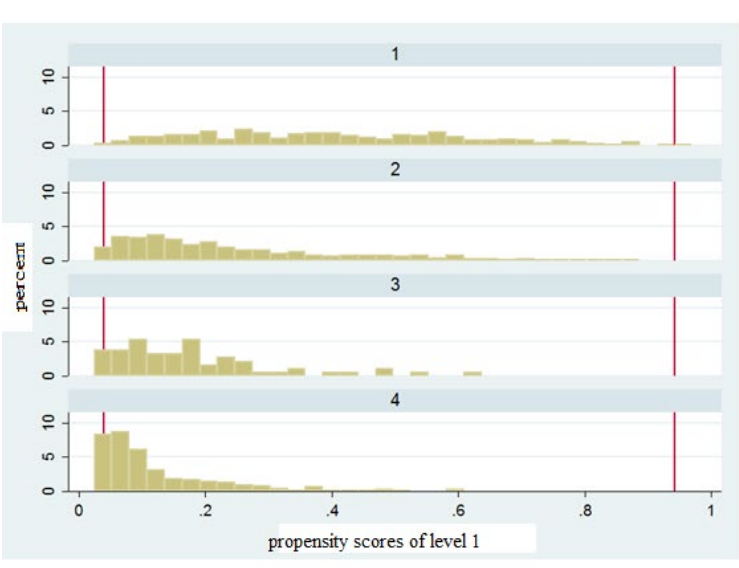

(a)

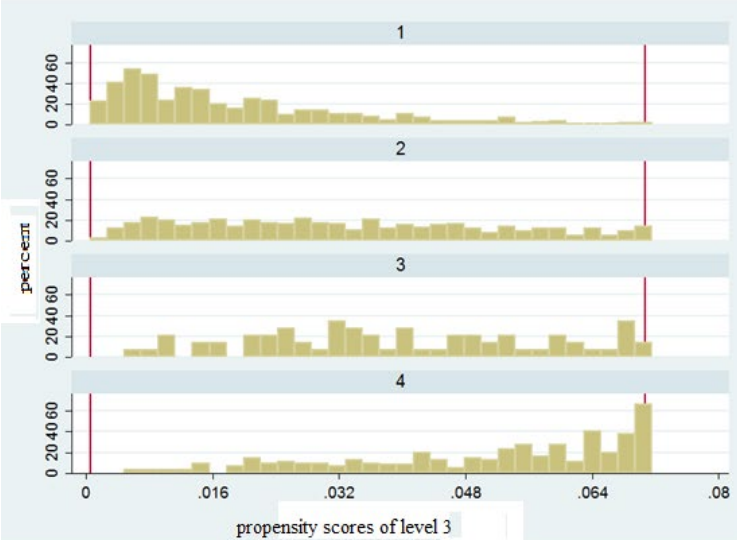

(c)

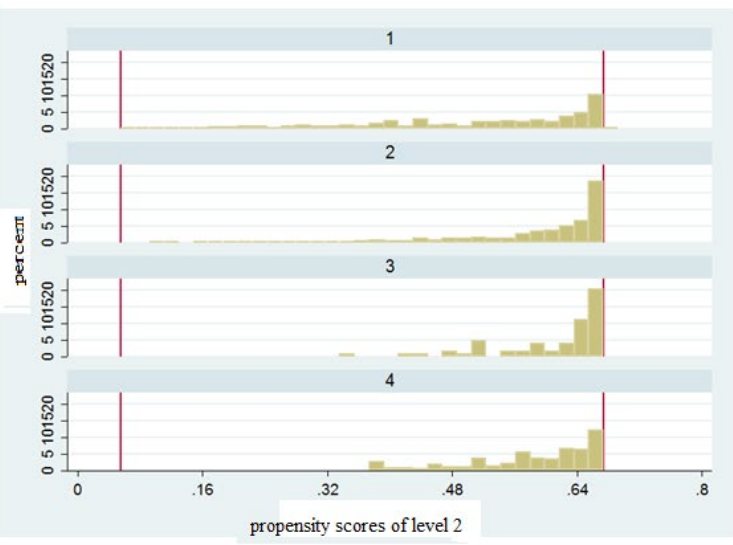

(b)

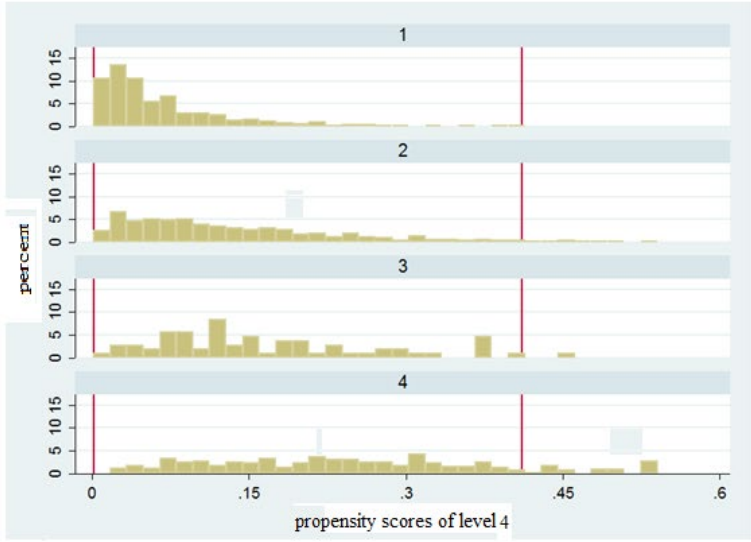

(d)

Figure 1. (a). The distruction of Level 1 partiction (b). The distruction of Level 2 partiction (c). The distruction of Level 1 partiction (d). The distruction of Level 2 partiction

Confounding variables. The key to propensity score analysis is to select the right confounding variables. In this study, confounding variables are the factors that confound the association between participation levels and attitudes toward engineering. They include the students' demographic information, social economic status, attitudinal characteristics and cognitive characteristics and the school characteristics (Jiang \& McComas, 2015). The following were identified as covariates based on relevant studies: students' gender, schools, birthplace, parent education, family social economic status, family support of engineering activities and participation in outside engineering activities, STEM at school, teacher profiles, teaching resources and school culture (Fan \& Nowell, 2011).

\section{RESULTS AND DISCUSSION}

\section{Status of Student Participation in Engineering Practice}

Multinomial logistic regression was conducted at each participation level to estimate the probabilities. Accounting for confounding variables, each student had a certain probability of being assigned to one of the four levels of participation. This probability indicated the student's propensity score. The data indicated a good fitness for the logistic regression results $\left(p=0.000\right.$, pseudo $\left.R^{2}=0.1325\right)$. The results of the Receiver Operating Characteristic (ROC) test indicated that the selected confounding variables clearly explained the propensity score of the students' participation in engineering practice. Figure 1 represents the common support bounds from Level 1 (a) to Level 4 (d). The upper and lower bounds are illustrated using red vertical lines. For example, Figure 1 shows the distribution of Level 1 participation (upper graph) and the distribution of Level 2, 3 and 4 participation (lower graphs) with similar demographic backgrounds to Level 1 participation. The vertical axis refers to the percentage of students' participation level and the horizontal axis refers to the propensity score for attitude. Thus, the students whose propensity scores were outside of the common support region were not included. In these four figures, the distribution of the students' propensity scores in the common support region was also revealed and the sample for each level of engineering practice participation after matching was formed. This helped finalise the total number of students for analysis $(n=2,138)$. 
Table 3. Number of students at each participation level

\begin{tabular}{ccccc}
\hline & \multicolumn{2}{c}{ Original Sample $(\mathbf{N}=\mathbf{2 1 9 3})$} & \multicolumn{2}{c}{ Analytic Sample $(\mathbf{N}=\mathbf{2 1 3 8})$} \\
\hline Level & No. of students & Percentage/\% & No. of students & Percentage/\% \\
\hline Level 1 & 588 & 26.81 & 588 & 27.50 \\
\hline Level 2 & 1251 & 57.05 & 1229 & 57.48 \\
\hline Level 3 & 68 & 3.01 & 67 & 3.13 \\
\hline Level 4 & 286 & 13.04 & 254 & 11.88 \\
\hline
\end{tabular}

Table 4. MMW-S and number of students for each strata by participation level

\begin{tabular}{|c|c|c|c|c|c|c|c|c|}
\hline \multirow{2}{*}{ Stratum } & \multicolumn{2}{|c|}{ Level 1} & \multicolumn{2}{|c|}{ Level 2} & \multicolumn{2}{|c|}{ Level 3} & \multicolumn{2}{|c|}{ Level 4} \\
\hline & $\mathbf{N}$ & MMW-S & $\mathbf{N}$ & MMW-S & $\mathbf{N}$ & MMW-S & $\mathbf{N}$ & MMW-S \\
\hline 1 & 21 & 5.69 & 180 & 1.39 & 4 & 3.40 & 6 & 9.54 \\
\hline 2 & 59 & 1.96 & 231 & 1.10 & 8 & 1.70 & 22 & 2.60 \\
\hline 3 & 103 & 1.14 & 260 & 0.94 & 20 & 0.75 & 36 & 1.58 \\
\hline 4 & 170 & 0.69 & 293 & 0.87 & 18 & 0.75 & 63 & 0.90 \\
\hline 5 & 235 & 0.49 & 287 & 0.85 & 18 & 0.67 & 159 & 0.35 \\
\hline Total & \multicolumn{2}{|c|}{588} & \multicolumn{2}{|c|}{1251} & \multicolumn{2}{|c|}{68} & \multicolumn{2}{|c|}{286} \\
\hline
\end{tabular}

Table 5. Propensity score difference analysis results before and after weighting

\begin{tabular}{ccccc}
\hline Level of engineering practice & \multicolumn{2}{c}{ Before weighting } & \multicolumn{2}{c}{ After weighting } \\
\cline { 2 - 5 } participation (propensity score) & $\mathbf{F}$ & $\boldsymbol{p}$ & $\mathbf{F}$ & $\boldsymbol{p}$ \\
\hline Level 1 & 173.84 & $<0.01$ & 109.41 & $<0.01$ \\
\hline Level 2 & 85.16 & $<0.01$ & 71.34 & 0.0039 \\
\hline Level 3 & 0.69 & 0.4065 & 1.94 & 0.1634 \\
\hline Level 4 & 124.77 & $<0.01$ & 82.33 & $<0.01$ \\
\hline
\end{tabular}

Based on the propensity score obtained, each student was further matched to the four participation levels of engineering practice. Surprisingly, as Table 3 shows, the percentage of students at Level 2 (i.e., participated less than 5 times per semester) was quite high, constituting $57.05 \%$ of the total number of students $(n=1,251)$. The percentage of Level 3 students (i.e., participated 5 times or more per semester with an incomplete engineering process) was very low, constituting only $3.01 \%$ of the total number of students $(n=68)$. Finally, the percentage of Level 1 (i.e., no participation) and 4 (i.e., participated more than 5 times per semester with a complete engineering process) students was $26.81 \%(n=588)$ and $13.04 \%(n=286)$ of the total number of students, respectively. After matching, the data for 55 students, who were mostly at Levels 2 and 4, were discarded and not included in the following analysis. The data of the Level 1 and 3 students were in good shape. No further adjustment was made. The final data set consisted of $27.05 \%$ Level 1 students, $57.48 \%$ Level 2 students, $3.13 \%$ Level 3 students and $11.88 \%$ Level 4 students. Thus, almost half of the students were at Level 2 participation in engineering practice, with a participation frequency of less than 5 times per semester without a complete engineering process. A considerable percentage of the students did not participate in engineering practice throughout the semester. A small number of students reached Level 4, meaning that they had participated in engineering practice more than 5 times with a complete engineering process.

At each level, the students were further divided into five equal strata based on the estimated propensity score. Table 4 displays the number of students in each stratum and the corresponding marginal mean weighting through the stratification (MMW-S) weight of students in that stratum. This served as the basis for sample bias balancing and further analysis of the causal relationship between the students' participation in engineering practice and their attitudes toward engineering.

\section{Matching Test of Balance}

The difference between the propensity score before and after weighting was analysed to ensure that the four sample groups tested were balanced. The analysis of variance (ANOVA) revealed a decrease in the F score after weighting, indicating a good balance between inter-group variances (Table 5). The increase in the F score at Level 3 did not match well, as the Level 3 data were already in good shape before weighting.

\section{Causal Relationship Analysis after Weighting}

An ANOVA was conducted to explore the effect of the students' participation in engineering practice on their attitudes toward engineering under each attitude dimension of cognition, emotion and behavioural tendency. The 
Table 6. The impact of students' participation in engineering practice on their attitudes toward engineering

\begin{tabular}{|c|c|c|c|c|c|c|c|c|c|c|}
\hline \multirow{2}{*}{ Variable } & \multicolumn{2}{|c|}{ Level 1} & \multicolumn{2}{|c|}{ Level 2} & \multicolumn{2}{|c|}{ Level 3} & \multicolumn{2}{|c|}{ Level 4} & \multirow[b]{2}{*}{$\mathbf{F}$} & \multirow[b]{2}{*}{$\mathbf{R}^{2}$} \\
\hline & M & SD & $\mathbf{M}$ & SD & $\mathbf{M}$ & SD & $\mathbf{M}$ & SD & & \\
\hline \multicolumn{11}{|c|}{ Attitudes toward engineering } \\
\hline Before weighting & 75.15 & 0.47 & 80.74 & 0.28 & 78.85 & 1.13 & 86.27 & 0.46 & 85.16 & 0.10 \\
\hline After weighting & 76.03 & 0.69 & 80.53 & 0.29 & 78.11 & 1.63 & 85.02 & 0.75 & 26.72 & 0.07 \\
\hline \multicolumn{11}{|c|}{ Attitudes toward engineering (cognition) } \\
\hline Before weighting & 44.76 & 0.21 & 45.80 & 0.13 & 45.94 & 0.51 & 47.09 & 0.19 & 23.21 & 0.02 \\
\hline After weighting & 45.42 & 0.30 & 45.70 & 0.13 & 45.78 & 0.64 & 46.25 & 0.36 & 1.07 & 0.00 \\
\hline \multicolumn{11}{|c|}{ Attitudes toward engineering (emotion) } \\
\hline Before weighting & 25.15 & 0.27 & 28.71 & 0.15 & 27.74 & 0.64 & 31.81 & 0.25 & 11.11 & 0.12 \\
\hline After weighting & 25.45 & 0.41 & 28.62 & 0.15 & 27.22 & 0.97 & 31.51 & 0.36 & 41.46 & 0.12 \\
\hline \multicolumn{11}{|c|}{ Attitudes toward engineering (behavior tendency) } \\
\hline Before weighting & 5.24 & 0.10 & 6.24 & 0.72 & 5.18 & 0.32 & 7.37 & 0.15 & 50.60 & 0.06 \\
\hline After weighting & 5.16 & 0.16 & 6.21 & 0.07 & 5.11 & 0.39 & 7.25 & 0.22 & 24.18 & 0.06 \\
\hline
\end{tabular}

$\mathrm{p}^{*}>0.01$

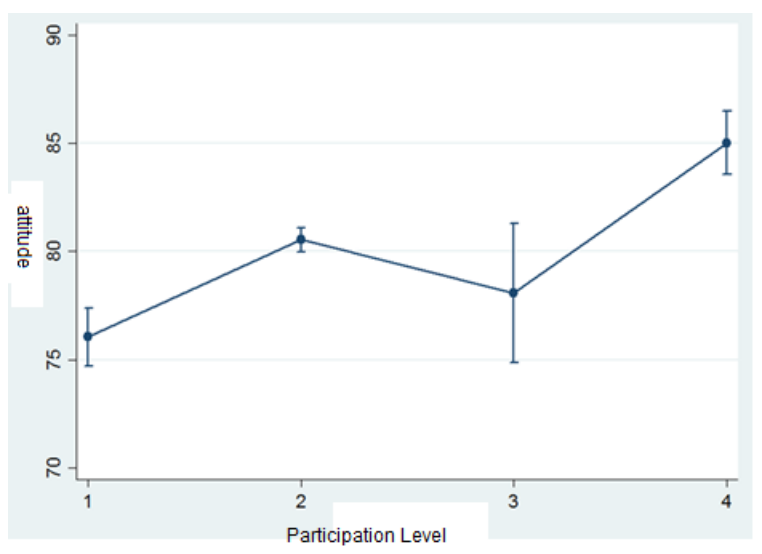

Figure 2. Students' participation in engineering practice and their attitudes toward engineering

results showed that the students' participation levels had a significant impact on their attitudes toward engineering at each dimension $\left(\mathrm{p}^{*}<0.01\right.$; Table 6$)$.

In general, the higher the participation level was, the better the students' attitudes were. Although the students' attitudes worsened at Level 3, they remained better than those at Level 1 (Figure 2). Figure 3 shows the causal relationship between the students' participation in engineering practice. Their attitudes toward engineering in each dimension demonstrated a moderate positive relationship. The higher the participation level, the better the attitudes in the cognition dimension. Furthermore, the improvement was gradual (Figure 3a). However, the impact of the students' participation was stronger in the emotion and behavioural tendency dimensions of attitude (Figure $3 \mathbf{b}$ and $3 \mathbf{c}$, respectively). The Level 1 students scored the lowest score in the emotion dimension of attitude. The students at Levels 2 and 3 scored higher in comparison, but the Level 3 students demonstrated a decrease in score. A similar pattern was observed for the behavioural tendency dimension of attitude. The only difference was that the Level 1 students already obtained comparative high scores in the behavioural tendency dimension of attitude. 


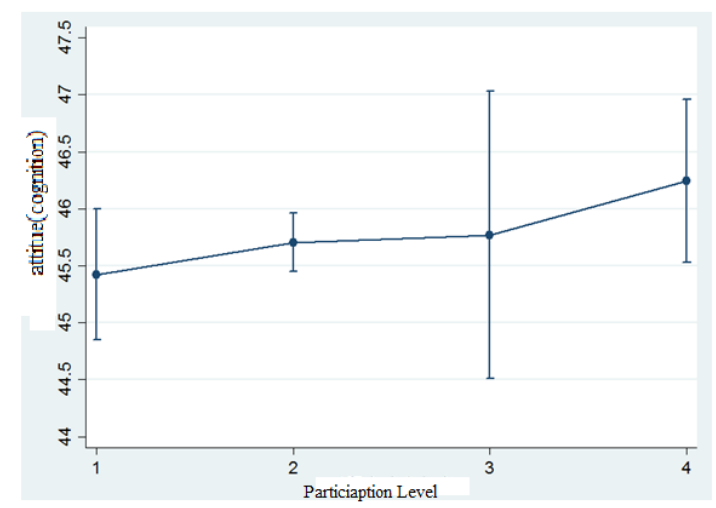

(a)

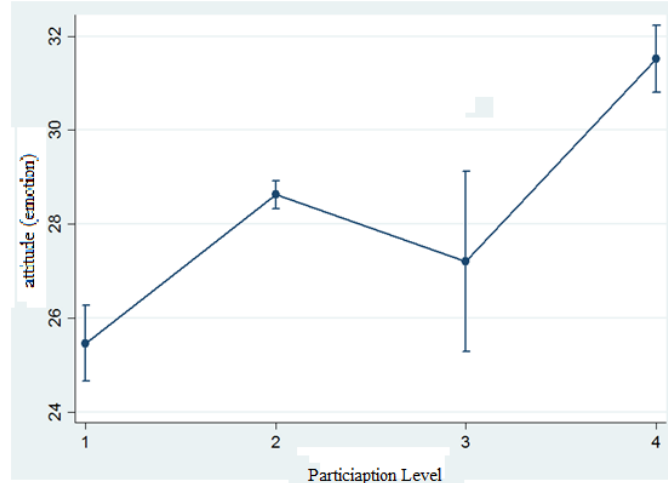

(b)

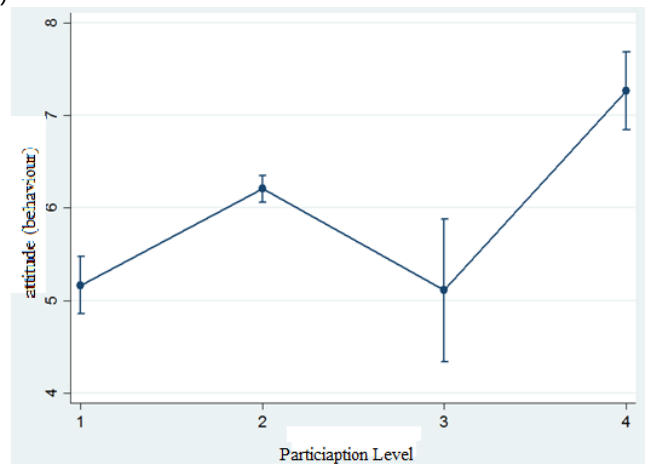

(c)

Figure 3. (a). Participation \& Attitude (Cognition) (b). Participation\& Attitude (Emotion) (c). Participation\& Attitude (Behavior)

The interference from confounding variables was mostly avoided via the use of propensity score analysis. Furthermore, the causal relationship between the students' participation in engineering practice and their attitudes toward engineering was identified. Generally, the higher the students' participation level was, the better their attitudes toward engineering were in all three attitude dimensions. Higher levels of participation indicated an increased frequency of participation and more opportunities to experience the engineering process.

Based on our definition, the Level 2 students experienced a low frequency of engineering practice participation ( $<5$ times per semester) and the Level 3 students had a comparative higher frequency of participation ( $\geq 5$ times per semester), but an incomplete engineering process. For the Level 4 students, the participation frequency was high ( $\geq 5$ times per semester) and the engineering process was complete. However, the impact of participation in engineering practice on attitudes toward engineering were complex. It did not strictly follow the pattern that the higher the participation level, the better the attitude. In this study, the Level 3 students' attitudes toward engineering worsened. The differences between the Level 2 and 3 students remained in the frequency of engineering practice and between the Level 3 and 4 students in practice completeness. The propensity score analysis showed that the Level 3 students' attitudes were worse than those of the students at Levels 2 and 4 . This showed that the frequency of participation had less influence on students' attitudes toward engineering than the completeness of the engineering process in which they participated. Compared to low participation frequency, long-term participation in incomplete engineering practice more negatively affected students' attitudes toward engineering. This reflected the decisive role of students' participation in complete engineering practice and its role in improving students' attitudes.

In incomplete engineering practice, students had limited opportunities to experience the engineering process and did not develop a comprehensive understanding of engineering practices. This may result in negative emotions toward engineering and low interest in engineering-related careers.

\section{CONCLUSIONS}

In this study, how junior secondary school students' participation in engineering practice affects their attitudes toward engineering was investigated using survey data and propensity score analysis. A considerable proportion (approximately $85 \%$ ) of students demonstrated low levels of engineering practice participation (i.e., Levels 1 and 2). A few students (approximately 3\%) experienced more engineering activities, but with incomplete engineering process. A small number of students (approximately 12\%) experienced a complete engineering process with 
comparative more exposure per semester. Overall, the students' participation in engineering practice was not high. This helps answer the first research question addressing the status of students' participation in engineering practice in junior secondary schools. The analysis results after matching and weighting affirmed the significant impact of students' participation in engineering practice on their attitudes toward engineering. This helps answer the second research question addressing the impacts of students' participation in engineering practice on their attitudes towards engineering. Generally, the students' attitudes toward engineering improved as participation level increased. Similar findings have been made in relevant studies. For example, Nam, Lee and Paik (2016) found that participation in an engineering-integrated science curriculum for a long period is a critical factor for influencing students' attitudes toward science and creating a positive image of engineering. Back (2015) found that sustained participation in regular physical activities have a positive impact on lifestyle, attitude and academic performance. Therefore, increasing the frequency of students' participation in the classroom is one important factor. Another important factor is that it is especially important for future engineers to be exposed to science clubs and competitions, local industry, talks, site visits and work experience (Woolnough, 1994).

However, higher student participation is not necessarily associated with better attitudes toward engineering. This unexpected result was found in the relationship between Level 3 participation and attitude scores. The Level 3 students had lower attitude scores in the emotion and behavioural tendency dimensions. Specifically, the Level 3 students experienced an incomplete engineering process. This reminds us that it is necessary for the schools and the teachers to provide students with various opportunities of experiencing engineering process probably in the pattern of problem solving, project based learning and inquiry based learning (Nadelson, et al., 2011) and to better facilitate students' development of knowledge and skills in engineering process (Bailey \& Szabo, 2006).

Furthermore, these students' negative attitudes toward engineering may suggest the imbalance of coverage of engineering design skills in the current science education and associate engineering or technology mostly with artefacts/products, not with the process of creation or invention (Chabalengula \& Mumba, 2017). The actual design of artefacts is highly covered in K-12 science education, with less emphasis on other design skills (e.g., identifying problems, testing and demonstration) related to the engineering process. This may prevent students development of skills and knowledge from being captured in the process and lead to missing opportunities to develop skills required to solve engineering-related problems. Another positive finding was revealed by the highest attitude scores being generated by the Level 4 students. Specifically, it suggests that frequent engineering practices with a complete engineering process enhance students' attitudes toward engineering and their motivations to pursue engineering careers. Thus, engaging students in high-quality and complete engineering practice at a certain frequency can have great potentials on improving their attitudes toward engineering.

\section{STUDY IMPLICATIONS}

Designing and implementing various forms of engineering practice both in and out of school are necessary and significant to enrich students' various experiences with engineering activities. Taking limited class time into consideration, the significance of out-of-school engineering practice to providing students with access to highquality engineering practice is self-evident and a good supplement for engineering learning (Kotys-Schwartz et al., 2011). To design and implement diverse out-of-school or extra-curricular forms of engineering practice, it is necessary to engage extensive resources from society and to coordinate with both in-school and out-of-school stakeholders (i.e., family; Cardella et al., 2013). Schools can collaborate with museums, science parks and research institutes to plan and execute engineering practice opportunities, seminars or exhibits of various forms, thus enabling students to experience engineering during out-of-school visits and interact with different communities (Bell, 2009; Burrows et al., 2018). Schools can also partner with factories and enterprises to provide students with engineering practice opportunities.

Meanwhile, with limited opportunities to experience difference engineering processes, many of the students regarded engineers as ' plasterers and brickies'. Similar research has suggested that secondary students have limited understanding of engineering and engineering education (Montfort, Brown, \& Whritenour, 2013). With such little understanding of engineering and engineering-related careers, students can hardly develop interest in engineering and preference towards engineering careers. Hence, implementing different kinds of vocational education activities in secondary schools is proposed. For example, schools can organise talks by engineers, who can introduce students to their daily jobs. This would help students develop a correct understanding of the engineering process and of engineering-related careers, thus encouraging students to pursue them. Schools can also collaborate with factories and enterprises to provide students with access to engineers and their workplaces. Immersing students in authentic engineering contexts and providing face-to-face interaction with real engineers may help them experience the authentic engineering process, deepen their understanding of engineering and develop their interest in engineering and related careers. Involving students in authentic engineering practice, particularly authentic modelling, facilitates their learning of models and modelling and improves their ability to apply knowledge to relevant issues in the context of real life (Prins et al., 2008). 
A multiple case study project showed that a key problem in engineering teacher professional development is the lack of a well-defined conceptual base for K-12 engineering. This may be closely related to inactive participation in engineering practice. The development of meaningful learning, teaching and assessment is problematic in the absence of a clear understanding of the conceptual base of the subject matter - in this case, K-12 engineering (Bransford, Brown, \& Cocking, 2000; Custer, Daugherty, \& Meyer, 2010). Currently, few clear policies and directives for engineering education at K-12 level in China exist. K-12 engineering education is sporadically discussed in policy documents for other subjects. Therefore, the systemic design and integration of engineering into science education is also rare. Teachers have few relevant training opportunities and schools lack the appropriate facilities for engineering education. Together this leads to the below-standard and incomplete educative engineering practice. In fact, engineering practice is far from real engineering education. To address these problems, policymakers should issue national level documents to guide the development of engineering education at the K12 level in a systemic fashion. Measures should be taken to provide teachers with proper training and to design appropriate instruction environments in which students can engage in engineering practice. The importance of engineering practice should be highlighted, educative forms of engineering practice should be standardised and the effectiveness of engineering education should be guaranteed. Engineering education should not only be discussed at the theoretical level using concepts and ideas, but also implemented in reality. Both the appropriate quantity and quality of engineering practice should be pursued.

With the backdrop of extensive international promotion of STEM education, educators in China should appreciate the significance of engineering in STEM education and the decisive role it can play in improving students' attitudes toward engineering and in developing engineering talents for the future (Brophy et al., 2008; Carr, Bennett IV, \& Strobel, 2012). Therefore, educational institutions at different levels should value engineering education and promote it via top-down approaches. This can help the cultivation of talents for the future development of the nation.

\section{STUDY LIMITATIONS}

Study limitations could not be avoided. The following limitations may affect our results and the accuracy of the data obtained on the effects of students' participation in engineering practice on their attitudes toward engineering. Specifically, the lack of examination of the content of engineering activities and of the impacts of the students' demographic characteristics, the scope of engineering integration subjects and the lack of observing teaching practices may have hidden other factors affecting students' attitudes toward engineering. Therefore, future research may explore the factors of curriculum design and implementation that affect students' attitudes toward engineering to obtain more causal data.

\section{ACKNOWLEDGEMENT}

The study is a part of work of the project: The Structure of Science Classroom integrating with the Engineering Design (16YJC880097), funded by the Humanity and Social Science Youth foundation of Ministry of Education, China.

\section{REFERENCES}

Abdulwahed, M. (2017). Technology Innovation and Engineering' Education and Entrepreneurship (TIEE) in Engineering Schools: Novel Model for Elevating National Knowledge Based Economy and Socio-Economic Sustainable Development. Sustainability, 9(2), 171. https:// doi.org/10.3390/su9020171

American Association for the Advancement of Science. (1995). Project 2061: Science for All Americans Summary. Washington, DC: American Association for the Advancement of Science

Apedoe, X. S, Reynolds, B., Ellefson, M. R., \& Schunn, C. D. (2008). Bringing engineering design into high school science classrooms: The heating/cooling unit. Journal of science education and technology, 17(5), 454-465. https:/ / doi.org/10.1007/s10956-008-9114-6

Back, K. W. (2015). The level of participation and attitude of school physical education and the relationship with academic sress, ego-resilience and psychological wellbeing of high school students. Indian Journal of Science and Technology, 8(15), 2-6. https://doi.org/10.17485/ijst/2015/v8i15/73097

Bailey, R., \& Szabo, Z. (2006). Assessing engineering design process knowledge. International Journal of Engineering Education, 22(3), 508-518.

Bamberger, Y. M., \& Cahill, C. S. (2013). Teaching Design in MiddleSchool: Instructors' Concerns and Scaffolding Strategies. Journal of Science Education and Technology, 22(2), 171-185. https://doi.org/10.1007/s10956-0129384-x 
Bazid, N. I., \& Umar, I. N. (2014). Students' level of participation, critical thinking, types of action and influencing factors in online forum environment. International Journal of Educational and Pedagogical Sciences, 8(12), 38183822.

Becker, F. S. (2010). Why don't young people want to become engineers? Rational reasons for disappointing decisions. European Journal of Engineering Education, 35(4), 349-366. https:/ / doi.org/10.1080/03043797.2010.489941

Bell, P. (2009). The role of informal environments and experiences in the learning of science. Subcommittee on Research and Science Education $\mathcal{E}$ Committee on Science and Technology. Retrieved from http:/ / www.washington.edu/alumni/partnerships/education/news/200905/bell_statement.pdf

Besterfield-Sacre, M., Moreno, M., Shuman, L., \& Atman, C. (2001). Self-assessed confidence in EC-2000 outcomes: A study of gender and ethnicity differences across institutions, Journal of Engineering Education, 90(4), 477489. https:// doi.org/10.1002/j.2168-9830.2001.tb00629.x

Bohner, G., \& Dickel, N. (2011). Attitudes and Attitude Change. Annual Review of Psychology, 62, 1-21. https://doi.org/10.1146/annurev.psych.121208.131609

Bransford, J. D., Brown, A. L., \& Cocking, R. R. (eds). (2000). How People Learn: Brain, Mind, Experience and School. Washington D.C.: National Academy Press.

Brookhart, M. A., Wyss, R., Layton, J. B., \& Stürmer, T. (2013). Propensity score methods for confounding control in non-experimental research. Circulation: Cardiovasccular Quality Outcomes, 6(5), 604-611. https:/ / doi.org/10.1161/CIRCOUTCOMES.113.000359

Brophy, S., Klein, S., Portsmore, M., \& Rogers, C. (2008). Advancing engineering education in P-12 classrooms. Journal of Engineering Education, 97(3), 369-388. https:/ / doi.org/10.1002/j.2168-9830.2008.tb00985.x

Burrows, A., Lockwood, M., Borowczak, M., Janak, E., \& Barber, B. (2018). Integrated STEM: Focus on Informal Education and Community Collaboration through Engineering. Education Sciences, 8(1), 4. https:/ / doi.org/10.3390/educsci8010004

Bybee, R. W. (2011). Scientific and Engineering Practices in K-12 Classrooms - Understanding A Framework for K12 Science Education. National Science Teachers Association, 35(4), 6-11.

Capobianco, B. M., Diefes-dux, H. A., Mena, I., \& Weller, J. (2013). What is an engineer? Implications of elementary school student conceptions for engineering education. Journal of Engineering Education, 100(2), 304-328. https:/ / doi.org/10.1002/j.2168-9830.2011.tb00015.x

Capobianco, B. M., Yu, J. H., \& French, B. R. (2015). Effects of engineering design-based science on elementary school science students' engineering identity development across gender and grade. Research in Science Education, 45(2), 275-29. https:/ / doi.org/10.1007/s11165-014-9422-1

Cardella, M. E., Wolsky, M., Paulsen, C. A., \& Jones, T. R. (2013). 120 th ASEE Annual Conference E Exposition.

Carr, R. L., Bennet IV, L. D., \& Strobel, J. (2013). Engineering in the K-12 STEM Standards of the 50 U.S. States: An Analysis of Presence and Extent. The Research Journal for Engineering Education, 101(3), 539-564. https:/ / doi.org/10.1002/j.2168-9830.2012.tb00061.x

Cerinsek, G., Hribar, T., Glodez, N., \& Dolinsek, S. (2013). Which are my future career priorities and what influenced my choice of studying Science, Technology, Engineering or Mathematics? Some insights on educational choice-Case of Slovenia. International Journal of Science Education, 35(17), 2999-3025. https:/ / doi.org/10.1080/09500693.2012.681813

Chabalengula, V. M., \& Mumba, F. (2017). Engineering design skills coverage in K-12 engineering program curriculum materials in the USA. International Journal of Science Education, 39(9), 1-17. https:/ / doi.org/10.1080/09500693.2017.1367862

Custer, R. L., Daugherty, J. L., \& Meyer, J. P. (2010). Formulating a Concept Base for Secondary Level Engineering: A Review and Synthesis. Journal of Technology Education, 22(1), 4-21. https:// doi.org/10.21061/jte.v22i1.a.1

Dankenbring, C., Capobianco, B. M., \& Eichinger, D. (2016). Engineering Encounters: How to develop an engineer design task. International Journal of Science and Mathematics Education, 14(5), 825-845. https://doi.org/10.1007/s10763-015-9626-5

David. E. E. (1987). A National Action Agenda for Engineering Education: A report. American Society for Engineering Education.

Dong, X. S., \& Liu, X. W. (2017). A review of engineering education in China: History, present and future. 2017 ASEE International Forum.

Eagly, A., \& Chaiken, S. (1993). The Psychology of Attitudes. Orlando, FL, US: Harcourt Brace Jovanovich College Publishers. 
Falco, L. D., \& Summers, J. J. (2019). Improving career decision self-efficacy and STEM self-efficacy in high school girls: Evaluation of an intervention. Journal of Career Development, 46(1), 62-76. https:/ / doi.org/10.1177/0894845317721651

Fan, X., \& Nowell, D. L. (2011). Using propensity score matching in educational research. Gifted Child Quarterly, 55(1), 74-79. https:/ / doi.org/10.1177/0016986210390635

Felder, R. M., \& Brent, R. (2005). Understanding Student Difference. Journal of Engineering Education, 94(1), 57-72. https:// doi.org/10.1002/j.2168-9830.2005.tb00829.x

Feng, M. (2016). The science and engineering practices in senior secondary biology classroom (Master Thesis). Hunan Normal University, China.

Franz-Odendaal, T. A., Blotnicky, K., French, F., \& Joy, P. (2016) Experiences and perceptions of STEM subjects, careers, and engagement in STEM activities among middle school students in the maritime provinces. Canadian Journal of Science, Mathematics and Technology Education, 16(2), 153-168. https:/ / doi.org/10.1080/14926156.2016.1166291

Fredricks, J. A., Blumenfeld P. C., \& Paris, A. H. (2004). School Engagement: Potential of the Concept, State of the Evidence. Review of Educational Research, 74(1), 59-109. https:/ / doi.org/10.3102/00346543074001059

Gao, Y. (2017). Integrating STEM Education into the Global Landscape in China. Science and Technology Trends. Retrieved from http://www.arpjournal.org/download/usr_downloadFile.do?requestedFile= 20171222104313650.pdf\&path=journal\&tp=isdwn\&seq=155

George, D., \& Mallery, P. (2003). SPSS for Windows step by step: A simple guide and reference. 11.0 update (4th ed.). Boston: Allyn \& Bacon.

Gerber, E, M., Olson, J. M., \& Komarek, R. L. D. (2012). Extracurricular design-based learning: preparing students for careers in innovation. International Journal of Engineering Education, 28(2), 317-324.

GETChina Insights. (2017). The STEM Education in China: There's a Long Way to Go. Retrieved from https:// medium.com/@EdtechChina/the-stem-education-in-china-theres-a-long-way-to-go-7e67a2c439f4

Gibbons, S. J., Hirsch, L., \& Rockland, R. (2004). Middle school students' attitudes to and knowledge about engineering. International Conference on Engineering Education, Gainesville, Florida, 16-21 Oct 2004.

Guzey, S. S., Harwell, M., \& Moore, T. (2014). Development of an Instrument to Assess Attitudes toward Science, Technology, Engineering, and Mathematics (STEM). School Science and Mathematics, 114(6), 271-279. https://doi.org/10.1111/ssm.12077

Guzey, S., \& Ring-Whalen, E. A. (2018). Negotiating science and engineering: an exploratory case study of a reformminded science teacher. International Journal of Science Education, 40(7), 723-741. https:/ / doi.org/10.1080/09500693.2018.1445310

Hayden, K., Ouyang, Y, Scinski, L., Olszewski, B., \& Bielefeldt, T. (2011). Increasing student interest and attitudes in STEM: Professional development and activities to engage and inspire learners. Contemporary Issues in Technology and Teacher Education, 11(1), 47-69.

Hazari, Z., Potvin, G., Cribbs, J. D., Godwin, A., Scott, T. D., \& Klotz, L. (2017). Interest in STEM is contagious for students in biology, chemistry, and physics classes. Science Advances, 3(8). https://doi.org/10.1126/sciadv.1700046 Retrieved from http://advances.sciencemag.org/content/advances/3/8/e1700046.full.pdf

Hippert, J., Stump, G., Husman, J., \& Kim, W. (2008). In Proceedings - Frontiers in Education Conference. 38th ASEE/IEEE Frontiers in Education Conference, FIE 2008 - Saratoga Springs, NY, United States.

Hua, L. (2017). The investigation of teacher perceptions on engineering integration in science curriculum at junior secondary schools (Master Thesis). East China Normal University, China.

Jiang, F., \& McComas, W. F. (2015). The Effects of Inquiry Teaching on Student Science Achievement and Attitudes: Evidence from Propensity Score Analysis of PISA Data. International Journal of Science Education, 37(3). https://doi.org/10.1080/09500693.2014.1000426

Karatas, F. O., Micklos, A., \& Bodner, G. (2010). Sixth-Grade Students' Views of the Nature of Engineering and Images of Engineers. Journal of Science Education and Technology, 20(2), 123-135. https:/ / doi.org/10.1007/s10956-010-9239-2

Katehi, L., Pearson, G., \& Feder, M. (Eds.). (2009). Engineering in K-12 education: Understanding the status and improving the prospects. Washington, DC: National Academies Press.

Kimmel, H., \& Rockland, R. (2002). Incorporating pre-engineering lessons into secondary science classrooms. Proceedings of the 32nd ASEE/IEEE Frontiers in Education Conference, Boston, MA. https:/ / doi.org/10.1109/FIE.2002.1157897 
King, G., \& Nielsen, R. (2018). Why Propensity Scores Should Not Be Used for Matching. Retrieved from https:/ / gking.harvard.edu/files/gking/files/psnot.pdf.

Kotys-Schwartz, D., Besterfield-Sacre, M., \& Shuman, L. (2011). Informal learning in engineering education: Where we are - Where we need to go. 2011 Frontiers in Education Conference (FIE). https://doi.org/10.1109/FIE.2011.6142836

Kőycú, U., \& de Vries, M. J. (2016). What preconceptions and attitudes about engineering are prevalent amongst upper secondary school pupils? An international study. International Journal of Technology and Design Education, 26(2), 243-258. https:/ / doi.org/10.1007/s10798-015-9305-4

Kutnick, P., Chan, Y. Y., Chan, K.-Y., Good, D., Lee, P.-Y., \& Lai, K. W. (2018). Aspiring to become an engineer in Hong Kong: effects of engineering education and demographic background on secondary students' expectation to become an engineer. European Journal of Engineering Education, 43(6), 824-841. https:/ / doi.org/10.1080/03043797.2018.1435629

Kutnick, P., Zhu, Z. Y., Chan, C. K. Y., Chan, Y. Y., Lee, P. Y., \& Lai, V. (2017). Attitudes and aspirations regarding engineering among Chinese secondary school students: comparisons between industrialising and postindustrial geo-engineering regions of Mainland China and Hong Kong). Compare: A Journal of Comparative and International Education, 48(4), 608-629. https:/ / doi.org/10.1080/03057925.2017.1347033

LaForce, M., Nobel, E.,\& Blackwell, C. (2017). Problem-based learning (PBL) and student interest in STEM careers: The roles of motivation and ability beliefs. Educational Sciences, 7(4), 1-22. https://doi.org/10.3390/educsci7040092

Liu, X. (2017). A New Framework of Science and Technology Innovation Education for K-12 in Qingdao, China. 2017 American Society for Engineering Education (ASEE) International Forum.

Maeng, J. L., Whitworth, B. A., Gonczi, A. L., Navy, S. L., \& Wheeler, L. B. (2017). Elementary science teachers' integration of engineering design into science instruction: results from a randomised controlled trial. International Journal of Science Education, 39(11), 1529-1548. https:/ / doi.org/10.1080/09500693.2017.1340688

Ministry of Education, People's Republic of China (MoE China) (2012). On the Establishment of National Practical Engineering Education Centers (in Chinese). Retrieved from https:/ /www.moe.gov.cn/publicfiles/business/ htmlfiles/moe/A08_zcwj/201207/139258.html

Ministry of Education. (2017). Compulsory Education, Standards for Primary School Science Curriculum. People's Republic of China. Retrieved from http://www.moe.gov.cn/srcsite/A26/s8001/201702/ W020170215542129302110.pdf

Montfort, D. B., Brown, S., \& Whritenour, V. (2013). Secondary Students' Conceptual Understanding of Engineering as a Field. Journal of Pre-College Engineering Education Research, 3(2), 1-12. https://doi.org/10.7771/21579288.1057

Moore, T. J., Tank, K. M., Glancy, A. W., \& Kersten, J. A. (2015). NGSS and the landscape of engineering in K-12 state science standards. Journal of Research in Science Teaching, 52(3), 296-318. https://doi.org/10.1002/tea.21199

Nadelson, L. S., Pyke, P., Callahan, J., Hay, A., Pfiester, J., \& Emmet, M.A. (2011). Connecting Science with Engineering: Using Inquiry and Design in a Teacher Professional Development Course. 118th ASEE Annual Conference and Exposition, June 26-29, 2011, Vancouver, BC, Canada.

Nam, Y. Y., Lee, S. J., \& Paik, S. H. (2016). The Impact of Engineering Integrated Science (EIS) Curricula on FirstYear Technical High School Students' Attitudes toward Science and Perceptions of Engineering. EURASIA Journal of Mathematics, Science \& Technology Education, 12(7). 1881-1907.

National Academy of Engineering. (2005). Educating the engineer of 2020: Adapting engineering education to the new century. Washington, DC: National Academies Press.

National Institute of Education Sciences. (2017). White Paper of STEM Education in China. Retrieved from http:/ / www.ckjy.org/wp-content/uploads/2017/09/STEM\%E6\%95\%99\%E8\%82\%B2\%E7\%99\%BD\%E7\% 9A $\%$ AE $\%$ E4\%B9\% A6.pdf

National Research Council. (1999). Engineering Tasks for the New Century; Japanese and U.S. Perspectives. Washington, DC: National Academies Press. Retrieved from https://www.nap.edu/read/9624/chapter/4

National Research Council. (2009). Engineering in K-12 education: Understanding the status and improving the prospects. Washington, DC: National Academies Press. https:/ / doi.org/10.17226/12635

National Research Council. (2010). Standards for K-12 Engineering Education? Washington, DC: The National Academies Press. https:/ / doi.org/10.17226/12990 
National Research Council. (2012). A Framework for K-12 Science Education: Practices, crosscutting concepts, and core ideas. Washington, DC: The National Academies Press. Retrieved from http:/ / www.nap.edu/catalog.php?record_id=13165

National Science Teachers Association. (1982). Science/technology/society: Science education for the 1980s (NSTA Position Statement). Washington, DC: National Science Teachers Association.

NGSS. (2013). Asking Questions and Defining Problems. NSTA. Retrieved from www.static.nsta.org/ngss/MatrixOfScienceAndEngineeringPractices.pdf

OECD. (2013). Education at a Glance 2013: OECD Indicators, OECD Publishing. https://doi.org/10.1787/eag-2013en

Perrin, M. (2004). Inquiry-Based Pre-Engineering Activities for K-4 Students. Journal of STEM Education: Innovations and Research, 5(3-4), 29-34.

Peterman, K., Daugherty, J. L., Custer, R. L., \& Ross, J. M. (2017). Analysing the integration of engineering in science lessons with the Engineering-Infused Lesson Rubric. International Journal of Science Education, 39(14), 19131931. https:/ / doi.org/10.1080/09500693.2017.1359431

Prins, G. T., Bulte, A. M. W., Driel, B. J. V., \& Pilot, A. (2009). Students' Involvement in Authentic Modelling Practices as Contexts in Chemistry Education. Research in Science Education, 39(5), 681-700. https:// doi.org/10.1007/s11165-008-9099-4

Puente, G. van Eijck, M., \& Jochems, W. (2011). Towards characterising design-based learning in engineering education: A review of the literature. European Journal of Engineering Education, 36(2), 137-149. https:/ / doi.org/10.1080/03043797.2011.565116

Rajecki, D. W. (1990). Attitudes. Sunderland, MA, US: Sinauer Associates.

Reid, N. (2006). Thoughts on attitude measurement. Research in Science and Technological Education, 24(1), 3-27. https:/ / doi.org/10.1080/02635140500485332

Rogers, G. F. C. (1983). The Nature of Engineering - A Philosophy of Technology. The MacMillan Press Ltd., London, UK.

Rosenbaum, P. R., \& Rubin, D. B. (1983). The central role of the propensity score in observational studies for causal effects. Biometrika, 70(1), 41-55. https://doi.org/10.1093/biomet/70.1.41

Seymour, E., \& Hewitt, N. M. (1997). Talking about leaving: Why undergraduates leave the sciences. Boulder, CO: Westview Press.

Sheppard, S., Colby, A., Macatangay, K., \& Sullivan, W. (2006). What is engineering practice? International Journal of Engineering Education, 22(3), 429-438.

Silver, A., \& Rushton, B. S. (2008). Primary-school children's attitudes towards science, engineering and technology and their images of scientists and engineers. International Journal of Primary, Elementary and Early Years Education, 36(1), 51-67.

Smail, B. (1993). Science for all pupils: gender issues in science education (p.89-99). In Sherrington, R (ed). The ASE primary teachers' handbook. Hemel Hempstead: Simon and Schuster.

Smith, E., \& White, P. (2019). Where do all the STEM graduates go? Higher education, the labour market and career trajectories in the UK. Journal of Science Education and Technology, 28, 26-40. https:/ / doi.org/10.1007/s10956018-9741-5

Strimel, G., \& Grubbs, M.E.(2016). Positioning Technology and Engineering Education as a Key Force in STEM Education. Journal of Technology Education, 27(2). Retrieved from https://scholar.lib.vt.edu/ejournals/JTE/v27n2/strimel.html

Tang, X., \& Wang, W. (2014). STEM integration: Analysis of the development of China's K-12 science education. Educational Research, 9, 61-68. (In Chinese).

The Next Generation Science Standards Executive Summary. (2013). Retrieved from https:/ / www.nextgenscience.org/sites/default/files/Final\%20Release\%20NGSS\%20Front\%20Matter\%20 -\%206.17.13\%20Update_0.pdf

The Organisation for Economic Co-operation and Development. (2008). Encouraging Student Interest in Science and Technology Studies. Global Science Forum. Retrieved from https:/ / www.bvekennis.nl/Bibliotheek/090070_OECD_science.pdf

Tseng, K. H., Chang, C. C., Lou, S. J., \& Chen, W. P. (2013). Attitudes towards science, technology, engineering and mathematics (STEM) in a project-based learning (PjBL) environment. International Journal of Technology and Design Education, 23, 87-102. https://doi.org/10.1007/s10798-011-9160-x 
UNESCO. (2010). Engineering: issues, challenges and opportunities for development. Retrieved from http:/ / unesdoc.unesco.org/images/0018/001897/189753e.pdf

Unfried, A., Faber, M., Stanhope, D. S., \& Wiebe, E. (2015). The development and validation of a measure of student attitudes toward science, technology, engineering, and math (S-STEM). Journal of Psychoeducational Assessment, 33(7), 622-639. https:// doi.org/10.1177/0734282915571160

Unlu, Z. K., Dokme, I., \& Unlu, V. (2016). Adaptation of the Science, Technology, Engineering, and Mathematics Career Interest Survey (STEM-CIS) into Turkish. Eurasian Journal of Educational Research, 63, 21-36.

Wiebe, E., Unfried, A., \& Faber, M. (2018). The relationship of STEM attitudes and career interest, EURASIA Journal of Mathematics, Science and Technology Education, 14(10), em1580. https:/ / doi.org/10.29333/ ejmste/92286

Woolnough, B. E. (1994). Factors affecting students' choice of science and engineering, International Journal of Science Education, 16(6), 659-676. https://doi.org/10.1080/0950069940160605

$\mathrm{Wu}$, Q. (2015). Science education in China: International experience and localization. Retrieved from https://www.akademisains.gov.my/download/science\%20education.pdf

Xie, Y., Zhang, C., \& Lai, Q. (2014). China's Rise as a Major Contributor to Science and Technology. Proceedings of the National Academy of Sciences of the United States, 111(26), 9437-9442.

Xu, K. (2008). Engineering education and technology in a fast-developing China. Technology in Society, 30(3-4), 265274. https:/ / doi.org/10.1016/j.techsoc.2008.04.024

Zhan, X. (2011). Integrating engineering into K-12 science education: definition, goals and methods. Basic Education, 7(6), 45-49. (In Chinese).

Zhang, Y. (2018). Experts call for emphasis on STEM education in China. Retrieved from https://www.chinadailyhk.com/epaper/pubs//chinadaily/2018/09/20/05.pdf

\section{http://www.ejmste.com}

